\title{
NMISA'S NEW 5 kN DEADWEIGHT FORCE STANDARD MACHINE
}

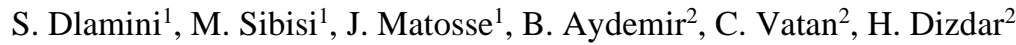 \\ ${ }^{1}$ National Metrology Institute of South Africa (NMISA), Tshwane, South Africa, sdlamini@nmisa.org \\ 2 TÜBİTAK National Metrology Institute (TUBITAK UME), Gebze, Kocaeli, Turkey
}

\begin{abstract}
:
This paper describes NMISA's new $5 \mathrm{kN}$ deadweight force standard machine. The machine has the capability to generate force in the range $50 \mathrm{~N}$ to $5 \mathrm{kN}$. The machine uncertainty is conservatively estimated at $0.008 \%$ across the entire measuring range. The weights are adjusted according to the gravity value measured in the laboratory. This machine is used for the calibration of force transducers in tension and compression.
\end{abstract}

Keywords: deadweight; force standard machine

\section{INTRODUCTION}

The National Metrology Institute of South Africa (NMISA) has acquired a new deadweight force standard machine (FSM). This is part of an ongoing project to improve calibration measurement capabilities (CMC) in the lower force ranges. Currently, in the lower force ranges, the NMISA force laboratory can only realise and disseminate the unit of force in the range $100 \mathrm{~N}$ to $1 \mathrm{kN}$ with a CMC of $0.03 \%$. The newly acquired FSM will realise and disseminate the unit of force in the range $50 \mathrm{~N}$ to $5 \mathrm{kN}$ with an improved $\mathrm{CMC}$ of $0.008 \%$ across its entire measurement range. This improved capability means that NMISA can provide traceability to the calibration industry in South Africa and neighbouring countries with the lowest uncertainty.

In this paper, the evaluation of the machine using a set of force transfer standards is discussed. A bilateral interlaboratory comparison (ILC) between NMISA and TUBITAK UME of Turkey was agreed upon. The results of the ILC are used to support the claimed machine uncertainty.

\section{MACHINE CHARACTERISTICS}

The machine's working principle is based on a stack of deadweights generating forces ranging from $50 \mathrm{~N}$ to $5 \mathrm{kN}$. The mass stack configuration of the machine is shown in Table 1.

This mass stack configuration can cover $500 \mathrm{~N}$, $1 \mathrm{kN}, 2 \mathrm{kN}$ and $5 \mathrm{kN}$ force capacities with ten steps for each capacity.
Table 1: Mass stack configuration

\begin{tabular}{|l|}
\hline 10 mass pieces, each generating $50 \mathrm{~N}$ \\
\hline 7 mass pieces, each generating $100 \mathrm{~N}$ \\
\hline 4 mass pieces, each generating $200 \mathrm{~N}$ \\
\hline 6 mass pieces, each generating $500 \mathrm{~N}$ \\
\hline
\end{tabular}

The mass pieces were designed and adjusted to generate nominal newton values using the local measurement of gravitational acceleration. This gravity value of $(9.7860985 \pm 0.0000005) \mathrm{m} \cdot \mathrm{s}^{-2}$ was measured by South Africa's Council for Geoscience and Geological Survey. The gravity value was also confirmed by the NMISA Kibble balance team using their standard gravimeter.

The $5 \mathrm{kN}$ deadweight FSM, shown in Figure 1, can be operated both manually and automatically.

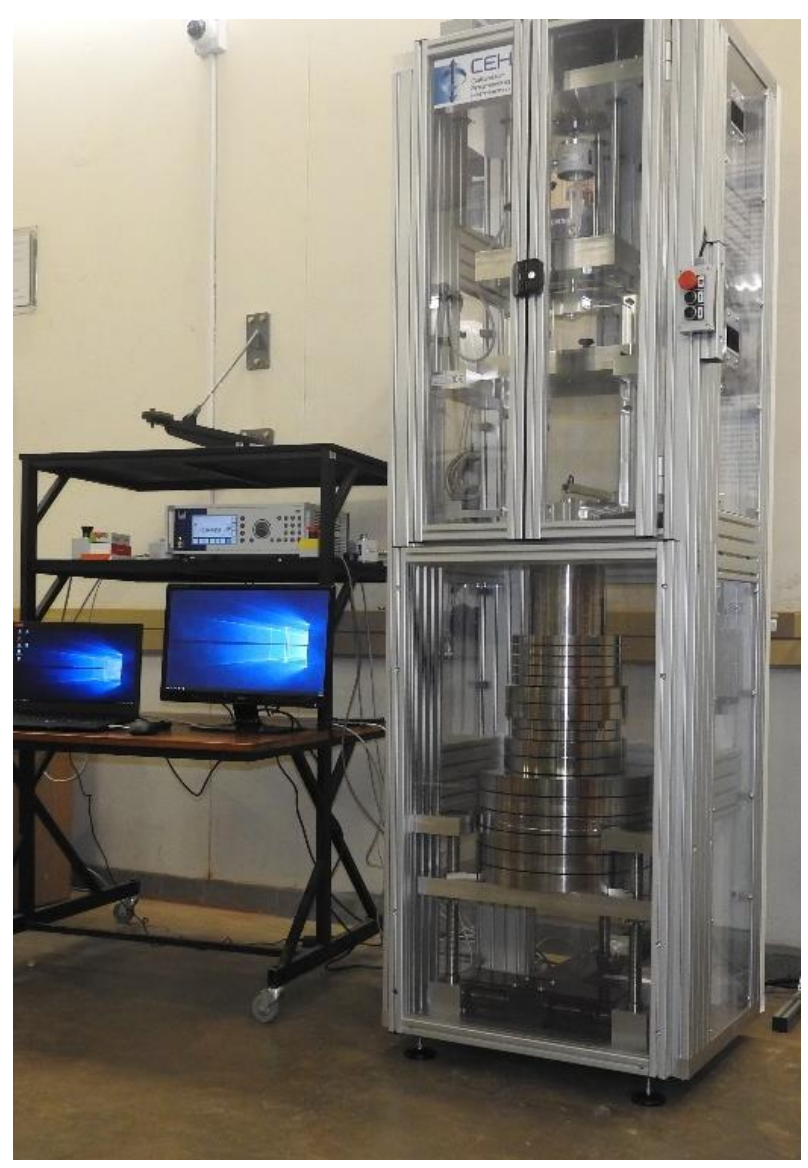

Figure 1: The $5 \mathrm{kN}$ deadweight FSM at NMISA 


\section{MACHINE EVALUATION}

The machine was evaluated through an ILC between NMISA and TUBITAK UME, using the equipment detailed in Table 2.

Table 2: Details of the transfer artefacts

\begin{tabular}{|l|l|l|l|}
\hline Device & Manufacturer & Model & Serial no. \\
\hline $\begin{array}{l}\text { Force } \\
\text { transducer }\end{array}$ & HBM & $\begin{array}{l}\text { Z30A } \\
(1 \mathrm{kN})\end{array}$ & 213313018 \\
\hline Readout & HBM & DMP41-T2 & 831891701 \\
\hline $\begin{array}{l}\text { Bridge } \\
\text { calibration } \\
\text { unit }\end{array}$ & HBM & BN100 & 001 \\
\hline
\end{tabular}

The force transfer standard was calibrated using the force standard machines detailed in Table 3.

Table 3: Details of the FSMs used

\begin{tabular}{|l|l|l|l|}
\hline \multirow{2}{*}{ Institute } & \multicolumn{3}{|l|}{ FSM capabilities } \\
\cline { 2 - 4 } & Type & Capacity & CMC \\
\hline TUBITAK UME & Deadweight & $11 \mathrm{kN}$ & $0.002 \%$ \\
\hline NMISA & Deadweight & $5 \mathrm{kN}$ & $0.008 \%$ \\
\hline
\end{tabular}

The measurements were performed following a protocol drafted jointly by NMISA and TUBITAK UME. The artefact was first measured at NMISA then couriered to TUBITAK UME for their measurements and thereafter back to NMISA for the final round of measurements. The transducer was installed into the calibration machine and plugged into the amplifier and energised for a minimum period of 12 hours before ILC measurements were taken. The DMP41 was used with the following settings: Absolute (ABS), $0.22 \mathrm{~Hz}$ Bessel filter, $5 \mathrm{~V}$ excitation voltage and $\pm 2.5 \mathrm{mV} / \mathrm{V}$ measuring range. The measurements were carried out at laboratory conditions of $(21 \pm 1){ }^{\circ} \mathrm{C}$ for temperature and $(45 \pm 10) \% \mathrm{RH}$ for relative humidity. The ILC artefact was measured at five positions relative to the axis of the machine $\left(0^{\circ}, 90^{\circ}, 180^{\circ}, 270^{\circ}\right.$ and $360^{\circ}$ ). Two measurement runs were applied at each position to show repeatability. Measurement runs were carried out with increasing force only in compression. Two minutes was the time allowed to achieve stability following loading and unloading of each force step. Only measurements from $40 \%$ of the artefact's capacity were considered for analysis.

The mean values and expanded measurement uncertainties were calculated for each of the measurements carried out first at NMISA (Round 1), then at TUBITAK UME, and finally at NMISA (Round 2), and are summarised in Table 4 and Table 5.

The relative deviation is calculated using equation (1).

Rel. dev. $=\frac{X_{\mathrm{NMISA}}-X_{\mathrm{TUBITAK} \text { UME }}}{X_{\mathrm{TUBITAK} \text { UME }}}$ where $X_{\text {NMISA }}$ (Round 1 or Round 2) and $X_{\text {TUBiTAK UME }}$ are the average deflection at each applied force for all positions.

Table 4: Deviation in the ILC measurements of NMISA from TUBITAK UME (reference)

\begin{tabular}{|r|c|c|c|c|c|}
\hline \multirow{2}{*}{$\begin{array}{c}\text { Force } \\
\text { / N }\end{array}$} & \multicolumn{4}{|c|}{ Mean deflection $\boldsymbol{X} / \mathbf{m V} / \mathbf{V}$} & \multicolumn{2}{c|}{$\begin{array}{c}\text { Relative deviation } \\
\text { from } \\
\text { TUBITAK UME }\end{array}$} \\
\cline { 2 - 7 } & $\begin{array}{c}\text { TUBITAK } \\
\text { UME }\end{array}$ & $\begin{array}{l}\text { NMISA } \\
\text { Round 1 }\end{array}$ & $\begin{array}{c}\text { NMISA } \\
\text { Round 2 }\end{array}$ & $\begin{array}{l}\text { NMISA } \\
\text { Round 1 }\end{array}$ & $\begin{array}{l}\text { NMISA } \\
\text { Round 2 }\end{array}$ \\
\hline 400 & 0.800515 & 0.800458 & 0.800494 & $-7.1 \mathrm{E}-05$ & $-2.6 \mathrm{E}-05$ \\
\hline 600 & 1.200719 & 1.200675 & 1.200743 & $-3.7 \mathrm{E}-05$ & $2.0 \mathrm{E}-05$ \\
\hline 800 & 1.600927 & 1.600880 & 1.600966 & $-3.0 \mathrm{E}-05$ & $2.4 \mathrm{E}-05$ \\
\hline 1000 & 2.001122 & 2.001070 & 2.001190 & $-2.6 \mathrm{E}-05$ & $3.4 \mathrm{E}-05$ \\
\hline
\end{tabular}

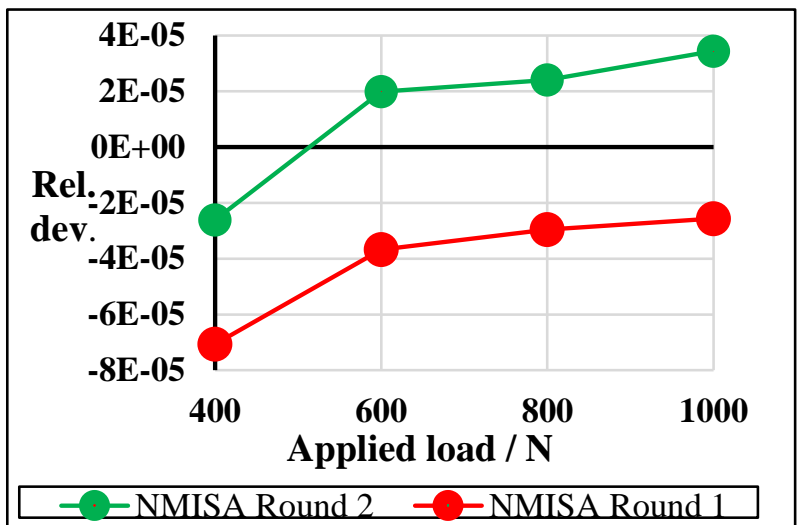

Figure 2: Relative deviation between NMISA and TUBITAK UME

The relative deviations between NMISA and TUBITAK UME are less than $8 \times 10^{-5}$ for the range investigated.

Furthermore, the normalised error $\left(E_{\mathrm{n}}\right)$ values are calculated for the ILC and used as a way of assessing measurement equivalence with respect to the uncertainty.

Table 5: Deviation and the relative expanded uncertainties of measurements for NMISA and TUBITAK UME.

\begin{tabular}{|c|c|c|c|c|c|}
\hline \multirow{2}{*}{$\begin{array}{c}\text { Force } \\
\text { / N }\end{array}$} & \multicolumn{2}{|c|}{$\begin{array}{c}\text { Relative deviation } \\
\text { from TUBITAK }\end{array}$} & \multicolumn{3}{|c|}{ Exp. Uncertainty $U(k=2)$} \\
\cline { 2 - 3 } \cline { 5 - 6 } & $\begin{array}{c}\text { NMISA } \\
\text { Round 1 }\end{array}$ & $\begin{array}{c}\text { NMISA } \\
\text { Round 2 }\end{array}$ & $\begin{array}{c}\boldsymbol{U}_{\text {TUBITAK UME }} \\
/ \%\end{array}$ & $\begin{array}{c}\boldsymbol{U}_{\text {NMISA }} \\
\text { Round 1 } \\
/ \%\end{array}$ & $\begin{array}{c}\boldsymbol{U}_{\text {NMISA }} \\
\text { Round 2 } \\
/ \%\end{array}$ \\
\hline 400 & $-7.1 \mathrm{E}-05$ & $-2.6 \mathrm{E}-05$ & 0.008 & 0.009 & 0.009 \\
600 & $-3.7 \mathrm{E}-05$ & $2.0 \mathrm{E}-05$ & 0.008 & 0.009 & 0.010 \\
800 & $-3.0 \mathrm{E}-05$ & $2.4 \mathrm{E}-05$ & 0.007 & 0.010 & 0.008 \\
1000 & $-2.6 \mathrm{E}-05$ & $3.4 \mathrm{E}-05$ & 0.006 & 0.010 & 0.008 \\
\hline
\end{tabular}

Equation (2) is used to calculate the $E_{\mathrm{n}}$ values.

$$
E_{\mathrm{n}}=\frac{X_{\text {NMISA }}-X_{\text {TUBITAK UME }}}{X_{\text {TUBITAK UME }} \sqrt{U_{\text {NMISA }}^{2}+U_{\text {TUBITAK UME }}^{2}}}
$$


where $X_{\text {NMISA }}$ and $X_{\text {TUBITAK UME }}$ are the average deflection at each applied force for all positions and $U_{\text {NMISA }}$ and $U_{\text {TUBITAK UME }}$ are the relative expanded uncertainties of measurements for NMISA and TUBITAK UME respectively.

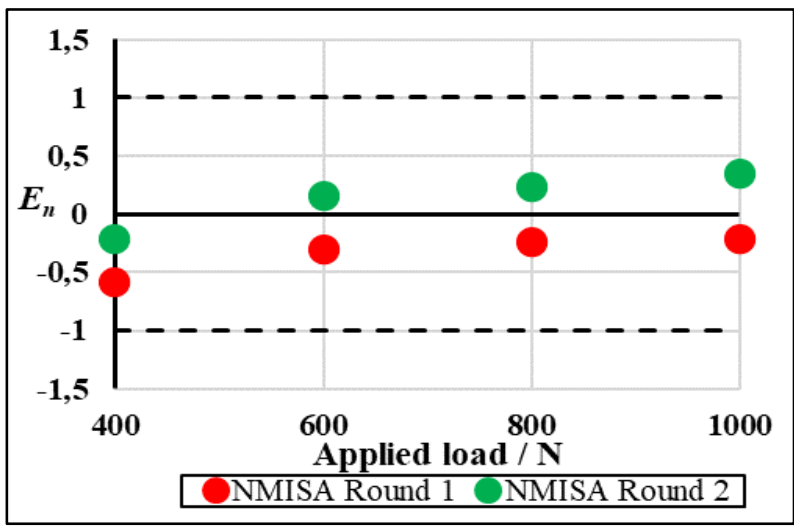

Figure 3: ILC results comparison (normalised error $E_{\mathrm{n}}$ )

As depicted in Figure 3, $E_{\mathrm{n}}$ values are below one across the ILC force range. This indicates good agreement in measurements with respect to the uncertainties.

To further support the stated ILC results between NMISA and TUBITAK UME, the NMISA force laboratory used a set of calibrated force transfer standards to evaluate the capabilities of the $5 \mathrm{kN}$ deadweight FSM. The transfer standards consisted of high accuracy force transducers (with capacities of $500 \mathrm{~N}, 1 \mathrm{kN}, 2 \mathrm{kN}$ and $5 \mathrm{kN}$ ) which were used to verify the machine across the measurement range. The transfer standards were first calibrated according to ISO 376 [1] at METAS in Switzerland using deadweight machines. They were then calibrated again at NMISA according to ISO 376 using the $5 \mathrm{kN}$ deadweight FSM and results compared to determine the degree of equivalence.

The relative deviations between the average deflections obtained by NMISA and METAS were calculated throughout the range and are given in Table 6. Repeatability and reproducibility for the measurements carried out at METAS are almost of the same order of magnitude as those obtained at NMISA.

The normalised error values were also calculated to determine equivalence, with respect to the measurement uncertainty between the calibration results of NMISA and METAS. The results are depicted in Figure 4.

The normalised error values are less than one throughout the measurement range thus showing good agreement in calibration results between NMISA and METAS.
Table 6: Relative deviation from METAS, repeatability $(b)$ and reproducibility $\left(b^{\prime}\right)$ comparison between NMISA and METAS calibrations

\begin{tabular}{|c|r|r|r|r|r|r|}
\hline \multirow{2}{*}{$\begin{array}{c}\text { Transducer } \\
\text { capacity }\end{array}$} & $\begin{array}{c}\text { Applied } \\
\text { force / N }\end{array}$ & \multirow{2}{*}{$\begin{array}{c}\text { Rel. } \\
\text { dev. }\end{array}$} & \multicolumn{2}{|c|}{ METAS } & \multicolumn{2}{c|}{ NMISA } \\
\cline { 4 - 7 } & & & $\boldsymbol{b} / \%$ & $\boldsymbol{b}^{\prime} / \%$ & $\boldsymbol{b} / \%$ & $\boldsymbol{b}^{\prime} / \%$ \\
\hline \multirow{4}{*}{$500 \mathrm{~N}$} & 50 & $-4.2 \mathrm{E}-05$ & 0.000 & 0.001 & 0.002 & 0.004 \\
\cline { 2 - 7 } & 250 & $7.6 \mathrm{E}-06$ & 0.000 & 0.001 & 0.001 & 0.032 \\
\cline { 2 - 7 } & 500 & $7.0 \mathrm{E}-06$ & 0.000 & 0.001 & 0.001 & 0.010 \\
\hline \multirow{4}{*}{$1 \mathrm{kN}$} & 700 & $1.4 \mathrm{E}-06$ & 0.000 & 0.001 & 0.000 & 0.002 \\
\cline { 2 - 7 } & 900 & $3.3 \mathrm{E}-06$ & 0.000 & 0.001 & 0.000 & 0.002 \\
\cline { 2 - 7 } & 1000 & $4.5 \mathrm{E}-06$ & 0.000 & 0.001 & 0.000 & 0.002 \\
\hline \multirow{4}{*}{$2 \mathrm{kN}$} & 1400 & $-1.4 \mathrm{E}-05$ & 0.001 & 0.000 & 0.001 & 0.002 \\
\cline { 2 - 7 } & 1800 & $-1.6 \mathrm{E}-05$ & 0.001 & 0.000 & 0.001 & 0.001 \\
\cline { 2 - 7 } & 2000 & $-1.6 \mathrm{E}-05$ & 0.001 & 0.000 & 0.001 & 0.001 \\
\hline \multirow{3}{*}{$5 \mathrm{kN}$} & 3000 & $-4.5 \mathrm{E}-05$ & 0.001 & 0.004 & 0.000 & 0.001 \\
\cline { 2 - 7 } & 4000 & $-4.8 \mathrm{E}-05$ & 0.001 & 0.004 & 0.000 & 0.001 \\
\cline { 2 - 7 } & 5000 & $-5.1 \mathrm{E}-05$ & 0.001 & 0.003 & 0.000 & 0.001 \\
\hline
\end{tabular}

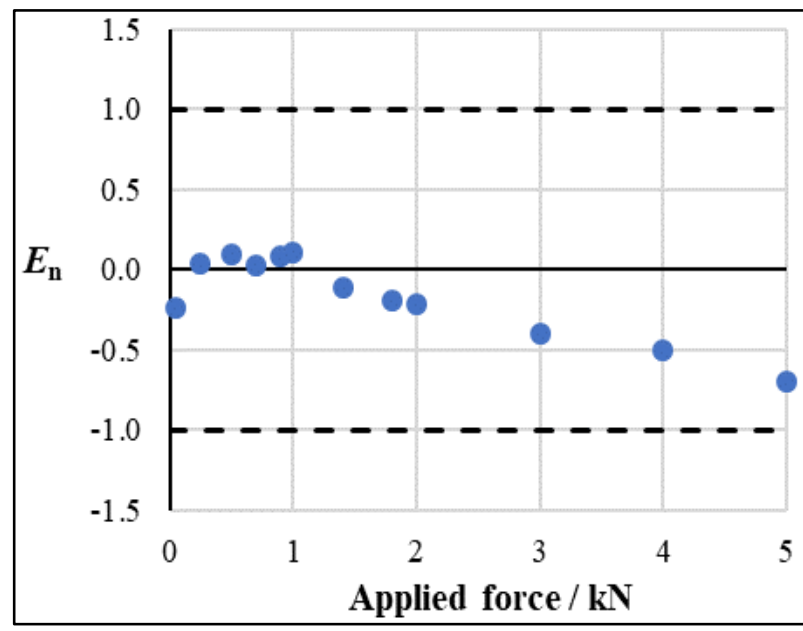

Figure 4: Results comparison (normalised error $E_{\mathrm{n}}$ )

\section{SUMMARY}

The normalised error values for the ILC measurements carried out between NMISA and TUBITAK UME using their deadweight FSMs are less than one for the entire comparison range. The maximum relative deviation observed for the ILC is $7 \times 10^{-5}(0.007 \%)$. There is also good agreement between the results of calibrations conducted according to ISO 376 by METAS and NMISA. The claimed uncertainty of $0.008 \%$ is therefore acceptable for the entire operational range of the $5 \mathrm{kN}$ deadweight FSM.

\section{REFERENCES}

[1] ISO 376:2011, Metallic Materials - Calibration of force proving instruments used for the verification of uniaxial testing machines, International Organization for Standardization, 2011. 